37 Arndt J, Riebenfeld D, Maier H, Weidauer H. Therapeutic efficacy and tolerability of brodimoprim in comparison with doxycycline in acute sinusitis in adults. J Chemother 1994;6:322-7.

38 Bockmeyer M, Riebenfeld D, Clasen B. Controlled study of brodimoprim and cephalexin in the treament of patients with acute sinusitis in general practice Clin Ther 1994:16:653-61.

39 Rahlfs VW, Macchiocchi A, Monti T. Brodimoprim in upper respiratory tract infections. Clin Drug Invest 1996;11:65-76.

40 Hayle R, Lingaas E, Hoivik HO, Odegard T. Efficacy and safety of azithromycin versus phenoxymethylpenicillin in the treatment of acute maxillary sinusitis. Eur J Clin Microbiol Infect Dis 1996;15:849-53.

41 Schultz KF, Chalmers I, Haves RJ, Altman DG. Empirical evidence of bias: dimensions of methodological quality associated with estimates of treatment effects in controlled trials. JAMA 1995;273:408-12.

42 Hamory BH, Sande MA, Sydnor A, Seale DL, Gwaltney JM. Etiology and antimicrobial therapy of acute maxillary sinusitis. J Infect Dis 1979; 139:197-202.

43 Nyffeneger R, Riebenfeld D, Macciocchi A. Brodimoprim versus amoxicillin in the treatment of acute sinusitis. Clin Ther 1991;13:589-95.

44 Skelton R, Maixner W, Isaacs D. Sinusitis-induced subdural empyema. Arch Dis Child 1992;67:1478-80.

45 Johnson DL, Markle BM, Wiedermann BL, Hanahan L. Treatment of intracranial abscesses associated with sinusitis in children and adolescents. J Pediatr 1988;113:15-23.
46 Evans FO, Sydnor JB, Morre WE, Moore GR, Manwaring JL, Brill AH, et al. Sinusitis of the maxillary antrum. N Engl J Med 1975;293:735-9.

47 Williams JW, Holleman DR, Samsa GP, Simel DL. Randomized controlled trial of 3 vs. 10 days of trimethoprim/sulfamethoxazole for acute maxillary sinusitis. JAMA 1995:273:1015-21.

48 Arason VA, Kristinsson KG, Sigurdsson JA, Stefandottir G, Molstad S, Gudmundsson S. Do antimicrobials increase the carriage rate of penicillin resistant pneumococci in children? Cross sectional prevalence study. BMJ 1996;313:387-91.

49 Seppala H, Klaukka T, Lehtonen R, Nenonen E, Huovinen P. Outpatient use of erythromycin: link to increased erythromycin resistance in group A streptococci. Clin Infect Dis 1995;21:1378-85.

50 Nissinen A, Gronroos P, Huovinen P, Herva E, Katila ML, Klaukka T, et al. Development of beta-lactamase-mediated resistance to penicillin in middle-ear isolates of Moraxella catarrhalis in Finnish children, 1978-1993. Clin Infect Dis 1995;21:1193-6.

51 Hansen JG, Schmidt H, Rosborg J, Lund E. Predicting acute maxillary sinusitis in a general practice population. BMJ 1995;311:233-6.

52 Lindbaek M, Hjortdahl P, Johnsen UL. Use of symptoms, signs, and blood tests to diagnose acute sinus infections in primary care: comparison with computer tomography. Fam Med 1996;28:183-8.

(Accepted 5 August 1998)

\title{
Understanding the culture of prescribing: qualitative study of general practitioners' and patients' perceptions of antibiotics for sore throats
}

\author{
Christopher C Butler, Stephen Rollnick, Roisin Pill, Frances Maggs-Rapport, Nigel Stott
}

\begin{abstract}
Objectives: To better understand reasons for antibiotics being prescribed for sore throats despite well known evidence that they are generally of little help. Design: Qualitative study with semi-structured interviews.

Setting: General practices in South Wales. Subjects: 21 general practitioners and 17 of their patients who had recently consulted for a sore throat or upper respiratory tract infection.

Main outcome measures: Subjects' experience of management of the illness, patients' expectations, beliefs about antibiotic treatment for sore throats, and ideas for reducing prescribing.

Results: Doctors knew of the evidence for marginal effectiveness yet often prescribed for good relationships with patients. Possible patient benefit outweighed theoretical community risk from resistant bacteria. Most doctors found prescribing "against the evidence" uncomfortable and realised this probably increased workload. Explanations of the distinction between virus and bacterium often led to perceived confusion. Clinicians were divided on the value of leaflets and national campaigns, but several favoured patient empowerment for self care by other members of the primary care team. Patient expectations were seldom made explicit, and many were not met. A third of patients had a clear expectation for antibiotics, and mothers were more likely to accept non-antibiotic treatment for their children than for themselves. Satisfaction was not necessarily related to receiving antibiotics, with many seeking reassurance, further information, and pain relief.

Conclusions: This prescribing decision is greatly influenced by considerations of the doctor-patient
\end{abstract}

relationship. Consulting strategies that make patient expectations explicit without damaging relationships might reduce unwanted antibiotics. Repeating evidence for lack of effectiveness is unlikely to change doctors' prescribing, but information about risk to individual patients might. Emphasising positive aspects of non-antibiotic treatment and lack of efficacy in general might be helpful.

\section{Introduction}

It has been known for many years that antibiotics modify the course of most sore throats only slightly if at all. ${ }^{2}$ Nevertheless, they are often prescribed ${ }^{3-6}$ despite accumulating evidence from trials. ${ }^{7-12}$ When patients expect antibiotics they are more likely to be prescribed, ${ }^{13}$ and when physicians perceive that patients expect antibiotics they are 10 times more likely to be prescribed. ${ }^{14}$ General practitioners describe this as the most uncomfortable decision about prescribing that they make. ${ }^{15}$ Antibiotic prescribing is rising in primary care, especially for respiratory tract conditions. ${ }^{16}$ There are growing concerns about cost, ${ }^{17}$ increasing workload for these usually self limiting conditions, ${ }^{10}{ }^{18}{ }^{19}$ and the rising prevalence of antibiotic resistant bacteria. ${ }^{20-23}$ The House of Lords Science and Technology Committee report on antibiotic resistance recommended prudent use of antibiotics, particularly in general practice. ${ }^{24}$ Large scale change in prescribing practice is associated with reduced antibiotic resistance. ${ }^{21}$

Interventions for changing this complex behaviour need to be based on a deep understanding of patients' and doctors' perceptions and problems. ${ }^{4{ }^{25}}$ We started a programme of research to address overprescribing of antibiotics for sore throats in primary care: we report here the first phase, which aims to achieve a better
Department of General Practice, University of Wales College of Medicine,

Llanedeyrn Health Centre, Maelfa, Cardiff CF3 7PN Christopher C

Butler,

lecturer

Stephen Rollnick, senior lecturer in general practice Roisin Pill, professor of general practice research

Nigel Stott, professor of general practice

Department of Dental Public Health, University of Wales College of Medicine,

Lansdowne

Hospital, Cardiff

Frances

Maggs-Rapport,

research officer

Correspondence to: Dr Rollnick genpract@cf.ac.uk

BMJ 1998;317:637-42 
understanding of the problem and generate ideas for interventions. Later phases of the research will further develop interventions, pilot them, and test them in clinical trials. We chose qualitative research methods for this phase of the research because our objectives were exploratory and hypothesis generating. ${ }^{26-28}$ Given the importance of both doctor and patient factors on the decision to prescribe, we included both clinicians and their patients in our research.

\section{Subjects and methods}

\section{Subjects}

Our goal was to interview doctors and patients from practices reflecting factors known to be associated with prescribing levels ${ }^{6930}$ rather than from statistically representative samples. We constructed a sampling frame by stratifying all practices in the Bro Taf Health Authority $(\mathrm{n}=133)$ into low, medium, and high deprivation groups (based on Townsend scores) and into small, medium, and large practices (based on numbers of partners). First, a practice was randomly selected from each of nine cells in the sampling frame, and then general practitioners were approached from the practice in random order. Each consenting general practitioner was asked to identify up to 10 consecutive patients (adults or children) consulting with sore throats within the two weeks before interview; we approached patients at random until one from each list had been interviewed.

\section{Interview procedure}

We conducted interviews with general practitioners (10-35 minutes) in surgeries after the patient list had been constructed. The practitioners were told that our purpose was not to audit practice but to understand their feelings about these consultations and antibiotic treatment. Interviews with general practitioners included questions about consultations for sore throats, their current practice, changes in their practice over time, the scientific evidence, and suggestions for action.

We interviewed patients (10-15 minutes) within two weeks after interviewing their general practitioner, and these took place in their own homes. They were told that the purpose was to understand their feelings about going to the doctor for colds and sore throats. Interviews were relatively brief to minimise inconvenience, and confidentiality was assured. The patients were asked about their experiences and views about their recent consultation and previous ones; self care practices, consulting thresholds, expectations of the consultation, what happened, satisfaction, their attitude towards and knowledge about antibiotics, and suggestions for reducing prescribing levels.

The local research ethics committee approved the study. We piloted the semi-structured interview schedules with four general practitioners and three patients. All questions were open. We added new questions as the interview process progressed. We stopped conducting interviews when no new themes were emerging, in line with the grounded theory approach. ${ }^{26}$

\section{Analysis}

Audiotaped interviews were transcribed and read twice by $\mathrm{CCB}$ and SR, then discussed with an experienced qualitative researcher (RP). Coding schedules were
Distribution of 21 general practices according to size (number of partners) and deprivation levels (Townsend scores)

\begin{tabular}{lccc} 
& \multicolumn{3}{c}{ Practice size } \\
\cline { 2 - 4 } Deprivation level & Small & Medium & Large \\
\hline Low & 2 & 3 & 3 \\
\hline Medium & 1 & 2 & 4 \\
\hline High & 1 & 1 & 4 \\
\hline
\end{tabular}

agreed and piloted. All interviews were double coded, by a researcher trained in qualitative methods (FM-R) and by $\mathrm{CCB}$ or SR; ambiguities were resolved in discussion. Categories were reduced to major themes through ongoing discussion between researchers and the re-reading of transcripts.

\section{Results}

Subjects

We approached 31 general practitioners by telephone; seven were too busy or declined without giving a reason, and four were on holiday or sick leave or were not contactable. Of the 21 general practitioners recruited, all but three had qualified in Britain, 13 held MRCGP, and all had been principals for between one and 28 years. While we successfully recruited practitioners from a wide range of practices (see table), we obtained fewer interviews from those in small practices in areas of high deprivation. Refusal by an individual practitioner in a small practice was more likely to result in the exclusion of the practice than was refusal of a practitioner working from a group practice.

The general practitioners who participated provided an average of 7.5 patient names each; only one failed to provide a list. We telephoned randomly selected patients from these lists, but if contact could not be made within a few days we selected another patient on the list. We telephoned 35 patients: 11 had incorrect or unobtainable telephone numbers, and seven declined to participate, resulting in 17 successfully completed interviews. Each of the nine stratification groups contained at least one patient, in some cases two. Four of the 17 patients were male, and five of the women had consulted their general practitioner on behalf of a child.

Since our goal was to enhance understanding and generate hypotheses rather than achieve significance in a statistical sense, ${ }^{26}$ our findings are not presented numerically. However, we give broad indications of the numbers of subjects who expressed each theme.

\section{Interviews with general practitioners}

\section{General perceptions of consultations for upper respiratory} tract infections

Most felt that, while the diagnostic aspect of these consultations was easy and often boring, management decisions were potentially complex. Although they recognised that patients came for reassurance, doctors felt that patients definitely "wanted something done" by the time they consulted and usually expected antibiotics. A typical clinician's opinion was, "You can't just say, 'It's viral, you don't need antibiotics, go away,' because they feel they're being fobbed off. They feel that their illness is not being taken seriously." Clinicians generally preferred to meet patients' expectations when reasonable to do so: "I really hate people leaving my room feeling really let down by not having their expectations 
met." All but one doctor felt that many patients had too low a threshold for consulting.

If a prescription was issued then the consultation was short and the patient seemed satisfied. However, prescribing antibiotics for these usually viral infections made clinicians feel compromised: "It does make me feel uncomfortable. I do feel as though I've been slightly used. Sometimes slightly abused as well."

Attempting to change patients' beliefs and expectations in the consultation was often perceived as time consuming and unrewarding. One practitioner said, "You spend 15 minutes trying to educate them, when they will go out disillusioned, come back the next day and see someone else, making you feel 5 minutes would be better spent just giving them a prescription and getting rid of them." However, some of the most satisfying consultations were when a patient expecting a prescription for antibiotics left the consultation accepting non-antibiotic management: "Obviously if I prescribe antibiotics then the patient is happy, but if they accept a rational explanation as to why they don't want antibiotics and seem happy enough with that, then that's equally, even more satisfying really."

Attitudes to current prescribing practices

Almost all clinicians acknowledged that antibiotics were prescribed too often for upper respiratory tract infections. All mentioned that, on average, antibiotics modified the course of these infections only slightly, if at all, in clinical trials. However, most felt that this evidence was not "watertight" and that antibiotics may help some patients. Although a minority mentioned bacterial resistance as a potential problem, this was seen as a community issue whereas the general practitioners' priority was the well being of the individual patient. Most felt that prescribing narrow spectrum antibiotics could do little harm. One clinician said, "In a way it would be better for the community that so many people would not take antibiotics, but I have a feeling that for the individual it is better for him or for her to take antibiotics. So here is a little bit of conflict of interest in a way ... now antibiotics are cheap and no harm is done if antibiotics are prescribed once or twice a year for an upper respiratory tract infection or a little bronchitis. Now why should I deprive my patients?”

However, almost all said they prescribed more than they would like to for these conditions. All but one believed they were "average" or "below average" prescribers of antibiotics for upper respiratory tract infections.

\section{Explanations for irrational prescribing}

Almost every practitioner mentioned that prescribing decisions for these conditions could have an important impact on the therapeutic power of the doctor-patient relationship. One said, "It may be later on in their life or your career you actually need to get messages across which are very much more important, and if there has been a history of perhaps confrontation then that's not too easy." The vast majority said they had increased their prescribing as their knowledge of their patients increased. Many were concerned to preserve and build relationships with their patients, and it was not worth jeopardising this "for the sake of a prescription for penicillin V." One clinician stated, "I think when I was a young fiery GP trainee I used to try and not give anti- biotics and now I'm softening and I give antibiotics more than I used to ... I'm quite well aware of the lack of firm evidence that antibiotics treat URTIs and that in terms of evidence based medicine we overprescribe antibiotics, but my own view is that I don't really care ... your goals at the end of the conversation is for both you and the mother and the baby to be satisfied."

If antibiotics were not prescribed many doctors believed that patients who really wanted them would eventually obtain them from other doctors and have a better relationship with the prescribing doctor, especially if the patient's condition had deteriorated in the meantime. Other commonly cited reasons for "giving patients the benefit of the doubt" were pressure of time, not having the energy to resist demand, fear of medicolegal problems if the patient deteriorated, and being perceived as "having done nothing" for patients.

\section{Consequences for workload}

While almost all acknowledged that prescribing might reduce workload in the short term (a quick consultation and reduction of the risk of an after hours visit), the vast majority recognised that prescribing antibiotics probably increased workload in the long term. Patients learned to associate their recovery with antibiotics and so consulted in the future when faced with similar illnesses. Hence doctors had created "a stick to beat our own backs."

\section{Everyday practice}

Although many clinicians recognised that differentiating between bacterial and viral infections was not possible with any certainty on clinical grounds alone, they usually prescribed antibiotics if they thought there was a good chance that the infection was bacterial. The most common clinical pointers to bacterial infections in the minds of clinicians were green phlegm, pus on the tonsils, and toxicity. One clinician stated that the distinction between bacterium and virus was irrelevant to the prescribing decision, since he believed that neither responded particularly well to antibiotic treatment. Most said they would prescribe antibiotics if the patient looked very unwell, whatever the likely infecting agent.

Most attempted to explain to patients that viruses are not responsive to antibiotics, both to justify not prescribing and to express their professional concern when prescribing antibiotics for probable viral infections. Several said that patients often did not understand such microbiological explanations, and one said that his approach was simply to say that research shows these infections do not get better any quicker with antibiotic treatment.

About half said they often gave patients a prescription but asked them to wait a few days before deciding to take the medicine (a delayed prescription strategy), and an equal number said that they promised easy access for review for those who were not given a prescription for antibiotics.

Only one clinician said she asked patients which treatment they hoped to obtain, while two said that patients might interpret such inquiry as confrontational. Two said they tried to "tune in" to patients' expectations using indirect, largely non-verbal cues. 
Ways to reduce prescribing

National media campaigns were the commonest suggestion for action, but several clinicians doubted their value. The internet as an educational resource was also mentioned. Suggestions for practice based initiatives included leaflets and posters, although a few doubted the effectiveness of written materials, and three said they could be counterproductive, increasing anxiety and workload. A few felt that nursing staff and health visitors in particular could be used through their contact with existing groups, providing education about self care for self limiting infections.

Within the consultation, clinicians felt that taking the patient's concerns seriously could reduce prescribing. One commented, "tune in and recognise what the mother is feeling and recognise her anxieties, and that's terribly important. The other thing you've got to do is not only recognise the mother's anxieties but relay to her that you recognise them." Several thought it important to explore patients' expectations: "Unless you find out what they're really in there for and how strongly they expect a prescription, I think you're not going to deal with the consultation as effectively." Others stressed the value of examining patients thoroughly; exploring their knowledge of possible side effects and resistant bacteria, explaining that antibiotic treatment might mean reduced efficacy if children became seriously ill and explaining trial evidence for lack of efficacy; giving patients control through providing easy access for review if their condition deteriorated and the delayed script strategy; and explaining that the decision not to prescribe was out of concern for the patient's health rather than through financial or other external pressures.

\section{Patient interviews}

What patients wanted

A third of patients had a clear expectation of receiving antibiotics. A few felt particularly strongly about this: "I get a lot of green phlegm, so from my point of view, speed is essential. It doesn't matter which doctor I see because I know what I want. I have a goal to go for. I have to go and get penicillin." Others, despite expecting antibiotics, said that they were more amenable to alternative management.

The remaining patients (about two thirds) most commonly said that they had consulted for reassurance: one man feared that he had cancer. Some said that they would also have liked a good explanation and advice on prevention. In addition, some wanted pain relief for themselves and their children. This group was evenly split between those who definitely didn't like or want antibiotics and those who could be encouraged to take them if the doctor felt it was important.

Four of the five mothers in this sample were happier to accept non-antibiotic solutions for their children than for themselves, including one woman who felt strongly that she needed antibiotics for herself. Three mothers expressed concern about "bothering" the doctor with potentially minor complaints, one even to the point of hoping that embarrassment could be saved by the discovery of a serious problem: "I think I was hoping that the doctor would tell me that it wasn't just a cold. I was hoping-it sounds terrible maybe-but I was hoping there was something wrong with him." In contrast, two other mothers described feeling quite comfortable to visit a particular doctor, who was apparently happy for them to consult with these problems.

How were their needs met?

Only one patient openly expressed her expectations to the doctor. The rest awaited the outcome of the doctor's examination and decision making. The overwhelming majority said that they didn't state their expectations because it was the doctor's responsibility to decide what should happen: "I'm no doctor. If I walked in and said, 'I want antibiotics for a throat infection.' Well that's their job, you know what I mean?”

All patients described a physical examination, yet few recalled discussions about expectations for antibiotics. Nevertheless, there seemed to be a reasonable degree of congruence between patients' expectations and outcome: of the third of the sample who consulted expecting antibiotics, all but one received a prescription for antibiotics. The exception was the one patient who had made her expectation explicit. However, she was content with non-antibiotic management because of her good relationship with her doctor (who had been supportive during bereavement) and because of the quality of the information he provided about antibiotics.

Among the remaining patients (who had no firm expectation of receiving antibiotics), some received a prescription, while others did not. The mothers of children not prescribed antibiotics were happy to accept this outcome, with the possible exception of one, who said that doctors these days were too ready to say, "everything is a virus." Dissatisfaction with the consultation was not necessarily related to the prescription of antibiotics (most who really wanted them got them). The lack of a clear explanation and the feeling of being rushed in the consultation were common causes of dissatisfaction:

Interviewer: "If the doctor had to do it differently, what would you like him to do?"

Patient: "To explain to me why you can't have antibiotics, why there is no reason to give them to you, and what alternatives I can use. Because basically it was, 'you don't need antibiotics for this and it will go away,' and that was it. But how long does it take to go away?"

Expectations were not satisfied in several other cases. One man came for reassurance about cancer and was given an antibiotic, which he took as a reassuring signal. A teacher came for preventive advice and left with a steroid nasal spray when she had been hoping for "a method or some sort of explanation as to how I could avoid these things." A mother came for reassurance and pain relief (under pressure from her family) and left with an unexpected antibiotic. A woman experiencing repeated episodes of sore throat apparently left without adequate explanation. A working woman, who didn't like "bothering" the doctor, received antibiotics on a second visit and wondered why she had not been given them on the first occasion. These accounts of dissatisfaction should not be confused with reports of conflict in the consulting room, which were absent from patients' accounts. Most patients described getting on well with their doctors.

\section{Patients'views about antibiotics}

Most patients indicated that antibiotics were by no means a trouble free solution to coughs, colds, and sore throats. Several mentioned the associations between 
antibiotics and thrush, rashes, and oral contraceptive failure. However, only one patient mentioned the association between antibiotics and resistant microorganisms. A sizeable minority clearly saw them as effective and as a preferred option: "I mean if I can't get [the children] better, well that's when they need antibiotics." Several reported what doctors often call a self fulfilling prophesy-that they got better with antibiotics within a few days, so they must be effective.

Explanations of the lack of effect of antibiotics against viruses did not necessarily leave patients satisfied about not receiving an antibiotic, either because they had not necessarily wanted one in the first place or because it did not match their understanding and need for pain relief: "I've had tonsillitis and throat infections about eight or nine times already this year .... They keep telling me sometimes it's tonsillitis, and sometimes it's just a throat infection, like it's only a throat infection, but it's painful. The last time I went to the doctor's she said that it was 'a throat infection and I can't give you antibiotics,' so in other words you've just got to grin and bear it, and I don't see why I should. You get frustrated because they don't really listen to you."

When asked how prescribing might be reduced among other patients, the most common suggestion was that doctors should offer a more detailed explanation. A few also expressed enthusiasms for media campaigns, school health promotion, and practice leaflets.

\section{Anticipating reactions to non-antibiotic treatment} General practitioners attempted to sense patients' flexibility and prescribe antibiotics as soon as they perceived resistance to a non-antibiotic approach. A general practitioner working in a large practice in a high deprivation area was generally proud of practice standards, but said, "The worst area of clinical practice in terms of good clinical medicine is the prescribing of antibiotics for upper respiratory tract infections . . . we've thrown in the towel."

His patient, a mother with a young child, presented with upper respiratory tract infections in herself and the child: "He's (the doctor) always very good.... As soon as I get a cold I get a sore throat, I've got to have antibiotics. I know it will clear within a few days." She was apparently not asked what she wanted; her doctor sensed her expectation and gave her an antibiotic immediately. This part of the consultation was over in less than two minutes. However, she stated, "With the baby, it's all new to me ... and the doctor will have more knowledge about him than me." She felt that the doctor sensed her greater flexibility and persuaded her to avoid antibiotics for her child.

\section{Discussion}

\section{Study limitations}

While we successfully interviewed practitioners from each of the nine stratification groups, it is possible that we missed important data obtainable only from the doctors who did not participate. Regarding the patient sample, doctors may have given us the names of patients who they perceived as amenable to participate in the research. Subjects may have consented because of their strong views. Although we also looked separately at data derived from five parents who consulted with children, this subsample was not, on its own, "purposeful." We did not specifically ask clinicians about the role and interpretation of non-verbal cues. This study relies on recall of consultations, and interviews were relatively brief.

\section{Patients' expectations and how they were met}

With one exception, the patients in our sample did not make their expectations of the consultation explicit to their doctor. Likewise, with one exception, doctors did not report asking patients about their expectations. Both parties saw the doctor-patient relationship as important and were reluctant to confront each other. This lack of explicitness could explain why some patients in our study received unwanted antibiotics and why many information needs were not met. Other researchers have pointed to doctors' overestimation of patients' expectation for antibiotic treatment. ${ }^{31-33}$ Our findings concur with research that found that doctors' judgment of patient expectations is a major influence on prescribing. ${ }^{143}$ Only a third of our study patients seemed clearly to want antibiotics. In line with results from other studies, ${ }^{10}{ }^{34-36}$ their satisfaction with the consultation did not simply revolve around whether antibiotics were prescribed: not being rushed and being taken seriously seemed more important.

For many doctors, these consultations are often easy and quick because antibiotics are prescribed, which apparently satisfies patients. Different management would have to fit into existing time constraints and be acceptable to patients. This confirms the view that a fruitful area of research may be the development of explicit strategies for briefly eliciting patients' expectations $^{37}$ and negotiating management acceptable to doctor and patient. Mothers in particular seemed ready to be flexible about whether their children received antibiotics.

\section{Doctors' information needs}

All the clinicians in this study were aware of evidence for the limited effect of antibiotic treatment and, as in other studies, ${ }^{33}$ accepted "non-scientific" prescribing for various reasons, including time pressure, wanting to do something active and signal sympathy, medicolegal concerns, and fear of losing patients to other doctors. Concern for financial implications of not prescribing are more acute in a fee for service milieu. ${ }^{38}$ However, many general practitioners stated that some individuals might benefit from antibiotics and felt that narrow spectrum antibiotics caused few problems. While often mentioned, antibiotic resistance was seen as a community problem, and the doctors saw the interests of their individual patients as more important. Future educational interventions might therefore stress information from research reports pointing to risk to the individual from the unnecessary consumption of antibiotics. ${ }^{39-44}$

\section{Empowering patients}

The justification for not prescribing antibiotics was usually made in negative terms; positive aspects could be emphasised instead. Patients in this and other studies expressed the belief that drugs can hamper effective development of the immune system. ${ }^{37}$

Explaining the distinction between bacterium and virus might not be as helpful as some think. Patients reported confusion, confirming some doctors' impression that they do not always grasp this distinction. 


\section{Key messages}

- Doctors know that antibiotics do not help most sore throat sufferers but try not to jeopardise relationships with patients over this issue

- Patients' expectations are seldom explicit, and satisfaction is not necessarily related to receiving an antibiotic: information and reassurance are sometimes more important

- Consulting techniques that make expectations explicit, preserve relationships, and facilitate acceptable management are important

- Opportunities for empowering patients who are not acutely ill could be better used, and emphasising positive aspects of non-antibiotic treatment, especially in children, could be fruitful

- Risks to individuals from unnecessary antibiotics (rather than trial evidence for marginal benefit) should be emphasised

Explaining the lack of responsiveness of sore throats to antibiotics in general may be more useful.

Doctors were divided about the value of national campaigns, but several saw the value of educating patients when they are not suffering from acute illnesses. Patients also wanted to know why they got these infections and what they could do help themselves. Opportunities within the practice for empowering patients to engage in self care could be exploited more, particularly for patient groups such as women attending for antenatal care or with their children for baby checks.

\section{Conclusions}

This study confirms the view that antibiotics are prescribed for a variety of complex reasons and that their symbolic effect for the doctor-patient relationship should not be underestimated. ${ }^{33}{ }^{35}$ Single, simple solutions are therefore unlikely to change prescribing habits. The problem is a cultural one and goes beyond doctors simply not knowing of the evidence from clinical trials. These interviews have generated several potential solutions that we plan to investigate in future phases of this research programme.

Contributors: CCB, SR, RP, and NS conceived and designed the study and were involved in writing the paper. RP, CCB, SR, and FM-R analysed the data. CCB and SR conducted the interviews. FM-R helped with analysis and conducted pilot work, analysing transcripts of previously taped consultations. Mrs Anne Cable transcribed the interviews and helped coordinate the study.

Funding: Wales NHS Office for Research and Development for Health and Social Care funded the study. CCB is supported by a research fellowship from Wales NHS Office for Research and Development for Health and Social Care.

Conflict of interest: None.

1 Whitfield MJ, Hughes AO. Penicillin in acute sore throat. Practitioner 1981;225:234-9.

2 Stott NCH. Management and outcome of winter upper respiratory tract infections in children aged 0-9 years. BMJ 1979;i:29-31.

3 McCaig LF, Hughes JM. Trends in antimicrobial drug prescribing among office based physicians in the United States. JAMA 1995;273:214-9.

4 Gonzales R, Steiner JF, Sande MA. Antibiotic prescribing for adults with colds, upper respiratory tract infections, and bronchitis by ambulatory care physicians. JAMA 1997;278:901-4.

5 Nyquist A, Gonzales R, Steiner JF, Sande MA. Antibiotic prescribing for children with colds, upper respiratory tract infections, and bronchitis. JAMA 1998;279:875-7.

6 Kuyvenhoven MM, De Melker RA, van der Velden K. Prescription of antibiotics and prescribers' characteristics. A study into prescribing antibiotics in upper respiratory tract infections in general practice. Fam Pract 1993;10:266-370.

7 Dagnelie CF, van der Graaf Y, De Melker RA. Do patients with sore throat benefit from penicillin? A randomized double-blind placebo-controlled clinical trial with penicillin V in general practice. Br J Gen Pract 1996; 46:589-93.

8 Mainous AG, Hueston WJ, Clark J. Antibiotics and upper respiratory infection. Do some folks think there is a cure for the common cold? J Fam Pract 1996;42:357-61

9 Herz MJ. Antibiotics and the adult sore throat-an unnecessary ceremony. Fam Pract 1988;5:196-9.

10 Little P, Williamson I, Warner G, Gould C, Gantley M, Kinmonth A. Open randomised trial of prescribing strategies in managing sore throat. $B M J$ 1997;314:722-7.

11 Howe RW, Millar MR, Coast J, Whitfield M, Peters TJ, Brookes S. A randomized controlled trial of antibiotics on symptom resolution in patients presenting to their general practitioner with a sore throat. BrJ Gen Pract 1997;47:280-4.

12 Del Mar CB, Galsziou PP. Antibiotics for the symptoms and complications of sore throat. In: Douglas R, Bridges-Webb C, Gkasziou P, Lozano J, Steinhoff M, Wang E, eds. Acute respiratory infections module, Cochrane Database of Systematic Reviews. The Cochrane Library. Cochrane Database of Systematic Reviews. The Cochrane Library.
Cochrane Collaboration; Issue 3. Oxford: Update Software, 1997. Updated quarterly.

13 Vinson DC, Lutz LJ. The effect of parental expectation on treatment of children with a cough: a report from ASPN. J Fam Pract 1997;37:23-7.

14 Cockburn J, Pit S. Prescribing behaviour in clinical practice: patients' expectations and doctors' perceptions of patients' expectations-a questionnaire study. BMJ 1997;315:520-3.

15 Bradley CP. Uncomfortable prescribing decisions: a critical incident study. BMJ 1992;304:294-6.

16 Davey PG, Bax RP, Newey J, Reeves P, Rutherford D, Slack R, et al. Growth in the use of antibiotics in the community in England and Scotland in 1980-93. BMJ 1996;312:613.

17 Little P, Willaimson I. Sore throat management in general practice. Fam Pract 1995;13:317-21

18 Mainous AG, Zoorob RJ, Oler MJ, Haynes DM. Patient knowledge of upper respiratory infections: implications for antibiotic expectations and unnecessary utilization.J Fam Pract 1997;45:75-83.

19 Little P, Gould B, Williamson I, Warner G, Gantley M, Kinmonth A. Reattendance and complications in a randomised trial of prescribing strategies for sore throat: the medicalising effect of prescribing antibiotics. BMJ 1997;315:350-2.

20 Swartz MN. Use of antimicrobial agents and drug resistance. N Engl J Med 1997;337:491-2.

21 Seppala H, Klaukka T, Vuopio-Varkila J, Muotiala A, Helenius H, Lager K, et al. The effect of changes in the consumption of macrolide antibiotics on erythromycin resistance in group A streptococci in Finland. $N$ Engl J Med 1997;337:441-6.

22 Hawkley PM. Action against antibiotic resistance: no time to lose. Lancet 1998;351:1298-9.

23 Hart CA. Antibiotic resistance: an increasing problem? BMJ 1998;316:1255-6.

24 House of Lords Select Committee on Science and Technology. Resistance to antibiotics and other antimicrobial agents. London: HMSO, 1998;

25 Hickner JM. Homely respiratory diseases revisited. J Fam Pract 1998; 46:119-20.

26 Glaser BG, Strauss AL. The discovery of grounded theory: strategies for qualitative research. Chicago: Aldine, 1967.

27 Britten N. Qualitative interviews in medical research. BMJ 1995; 311:251-3.

28 Britten N, Jones R, Murphy E, Stacy R. Qualitative research methods in general practice and primary care. Fam Pract 1995;12:104-14.

29 De Melker RA, Kuyvenhoven MM. Management of upper respirator tract infection in Dutch general practice. Br J Gen Pract 1991;41:504-7.

30 Campion PW, Gabriel J. Child consultation patterns in general practice: comparing high and low consulting patterns. BMJ 1984;288:1426-8.

31 Cartwright A, Anderson R. General practice revisited. London: Tavistock, 1981.

32 Virji A, Britten N. A study of the relationship between patients' attitudes and doctors' prescribing. Fam Pract 1991;8:314-9.

33 Comaroff J. A bitter pill to swallow: placebo therapy in general practice. Sociol Rev 1976;24:79-96.

34 Hamm RM, Hicks RJ, Bemben DA. Antibiotics and respiratory infections: are patients more satisfied when expectations are met? J Fam Pract 1996:43:56-62.

35 Kai J. What worries parents when their preschool children are acutely ill, and why: a qualitative study. BMJ 1996;313:983-6.

36 Kai J. Parents' difficulties and information needs in coping with acute illness in preschool children: a qualitative study. BMJ 1996;313:987-90.

37 Britten N. Patients' ideas about medicines: a qualitative study in a general practice population. Br J Gen Pract 1994;44:465-8.

38 Schwartz RK, Soumerai SB, Avron J. Physician motivation for nonscientific prescribing. Soc Sci Med 1989;28:577-82.

39 Mainous AG, Evans ME, Hueston WJ, Titlow WB, McCown LJ. Patterns of antibiotic-resistant Streptococcus pneumoniae in children in a day-care setting. J Fam Pract 1998;46:142-6.

40 Cherian T, Steinhoff MC, Harrison LH, Rohn D, McDougal LK, Dick J. A cluster of pneumococcal disease in young children in child care. JAMA 1994;271:695-7.

41 Herold BC, Immergluck LC, Maranan MC, Lauderdale DS, Gaskin RE, Boyle-Vavra S, et al. Community-acquired methicillin-resistant Staphylococcus aureus in children with no identified predisposing risk. JAMA 1998;279:593-8.

42 Dowell SF, Schwartz B. Resistant pneumococci: protecting patients through judicious use of antibiotics. Am Fam Physician 1997;55:1647-54.

43 Nava JM, Bella F, Garau J, Lite J, Morera M-A, Morati C, et al. Predictive factors for invasive disease due to penicillin-resistant Streptococcus pneumoniae: a population based study. Clin Infect Dis 1994:19:884-90.

44 Tan TO, Mason EO, Kaplan SL. Penicillin-resistant systemic pneumoccal infections in children: a reterospective case-control study. Pediatrics 1993;93:761-7.

(Accepted 14 August 1998) 